\title{
Educating the deliberate professional and enhancing professional agency through peer reflection of work integrated learning
}

Franziska Trede and Denise Jackson

\section{Biographical/contact details of author(s)}

Franziska Trede, Institute for Interactive Media and Learning, University of Technology, Sydney, Australia, PO Box 123, Broadway NSW 2007 Australia. Tel: +61 2 95144345. Email: Franziska.trede@uts.edu.au.

Denise Jackson, Centre for Innovative Practice, School of Business and Law, Edith Cowan University. Email: d.jackson@ecu.edu.au.

Franziska Trede is an Associate Professor in Higher Education and Professional Practice at the Institute for Interactive Media and Learning at the University of Technology Sydney. Her research interests include professional identity development, agency and educating deliberate professionals.

Denise Jackson is an Associate Professor and Director of Work Integrated Learning in the School of Business and Law, Edith Cowan University. Her research interests include graduate employability, transition from university to employment and graduate labour market outcomes, including underemployment.

\begin{abstract}
Educating reflexive, socially responsible and action-oriented future professionals who can contribute to a better future remains a core task of higher education. These graduate characteristics describe the deliberate professional. Within this article, we examine the value of a post- work-integrated learning peer reflection activity to foster professional agency and develop the deliberate professional in our students. Students participated in a post- work-integrated learning peer reflection activity, termed a huddle to signpost its informal yet respectful nature, and then completed a written reflection on the nature and value of this reflective experience. Findings demonstrate participants' engagement with as well as limitations towards becoming deliberate professionals. Implications for future use and further research of this peer reflection activity are offered. This study contributes new evidence that suggests that purposefully structured, dialogic and written post- work-integrated learning peer reflections are an effective approach towards developing professional agency and educating the deliberate professional.
\end{abstract}

Keywords: deliberate professional, agency, work integrated learning, reflection, peer reflection

\section{The need for a purposeful work-integrated learning pedagogy}

Preparing graduates with professional capabilities required for future practices remains a challenge for higher education. This is not only a challenge because the future job market is uncertain, but also because this demand of a future world-of-work that is increasingly complex, globalised and connected shifts the purpose of higher education (Connell, 2019). Future-looking practice capabilities have been predicted to include critical and creative thinking, communication skills and finding sustainable solutions to complex, global problems. Agency, coping with uncertainty and purposefully engaging with relentless rapid change are also considered important (OECD, 2013; Eteläpelto et al., 2013). 
As one of the many curriculum and pedagogical responses to these demands, universities are offering work-integrated learning as a strategic priority to equip students with these required capabilities, strengthening their employability and fostering professional identity development (Sachs et al., 2016). Barnett (2012) contended that purposeful, practice-based authentic learning experiences with appropriate pedagogy can advance not only knowledge but also personal development. Furthermore, students who are active, intentional and interdependent learners are considered to make the most of their work-integrated learning experiences (Billett, 2015). How students perceive themselves as future professionals including their strengths and weaknesses of working in teams are important career-wide attributes (Clark et al., 2015). This speaks to agency as a relational concept that requires supportive learning environments so that students are not limited to procedural, instrumental and technical reflections but also encouraged to reflect and learn from cultural, relational, political and ethical challenges encountered during work placements (Eteläpelto et al., 2013).

Too often however, the opportunity for critical, relational and collective learning during these placements is overshadowed by an emphasis on instrumental learning in hierarchical, organisational structures (Zepke and Leach, 2010). Work-integrated learning "should be a pedagogically supported experience, which includes reflection and articulation of the learning achieved" (Pegg et al., 2012, 45) and ideally conducted as a partnership with industry (University Australia, 2015).

\section{Theoretical concepts of the deliberate professional}

The idea that drove the conceptualisation of the deliberate professional was that students, teachers and practitioners need to reflect and act with more intention and purpose in order to improve practices, rather than have an unreflective approach which reproduces the status quo (Trede and McEwen, 2016). A deliberate professional is someone who can think for self, considers others and is curious to explore with others how things could be otherwise. Based on these conscious and thoughtful collective deliberations, they see possibilities in how to be and act in the world. Deliberate professionals make conscious choices, they take a stance, commit to action and take responsibility for the consequences of their actions.

The deliberate professional is underpinned by social and critical practice theories (Bourdieu, 1994; Arendt, 1998) that assert that practices are social, relational, cultural, technical, political and discursive in nature. This means that practice is not neutral or only technical. Practice is entrenched in power struggles and privilege (Bourdieu, 1994). The situatedness and interdependency of time and place in practice emphasise that cultural and ethical ways of knowing are important dimensions of practice and not subordinate to technical ways of knowing. A critical perspective of practice starts with the commitment to become aware of power differentials, privilege and injustices to then reduce and change them (Kemmis, 2012).

The concept of the deliberate professional is grounded in a pedagogy of deliberateness (Trede and McEwen, 2016) which builds on social and critical practice theory and draws on three key pedagogical concepts and series of processes: a) critical consciousness-raising (Freire, 1973); b) autonomy and self-directed learning; and c) critical thinking (Brookfield, 2012). Freire's critical consciousness-raising is a collective reflection process where learners focus on the context and relational nature of problems. Collectively becoming aware of wider complex conditions that shape practices ensures that solutions are addressing the roots of practice tensions. Autonomous and self-directed learning emphasises the idea that learners bring their values, experiences and interests to learning; they are not empty vessels. Reflections need to resonate and be relevant to the learner and the pedagogy of deliberateness embraces individual and social learning. Critical thinking then is the concept of questioning and being curious, in other words not accepting the way things are without having thought about them. Critical thinkers think for themselves and do not allow others to think for them (Newman, 2006).

\section{The four characteristics}

All three pedagogical concepts relate to each other. This can mean to listen and be guided or to speak up, both with purpose in a particular practice moment. This pedagogy emphasises a way of reflecting and acting in practice, that is thoughtful and actively engaged towards the betterment 
of self, a community of practice, and, ultimately, society. Used together, they help learners to critically understand the practices around them and to act purposefully. The four characteristics of the deliberate professional are:

- deliberating on the complexity of practice and workplace cultures and environments;

- understanding what is probable, possible and impossible in relation to existing and changing practices;

- taking a deliberate stance in positioning oneself in practice as well as in making technical decisions; and

- being aware of and responsible for the consequences of actions taken or actions not taken in relation to the 'doing', 'saying', 'knowing' and 'relating' in practice (Trede and McEwen, 2016).

\section{On agency}

Learning is an interactional, active and relational process that engages learners with sociocultural aspects that together make up learner agency (Eteläpelto, 2008). Student agency is an important prerequisite for productive work-integrated learning experiences (Billett, 2011). Agency can be understood as self-efficacy which is a belief that one is able to do something and make a difference. Agency has been conceptualised as an important aspect of professionalism (Littleton et al., 2012) and an employability skill (Knight and Yorke, 2006). Agency can be thought of as a prerequisite for learning, an in-the-moment learning in action as well as an outcome and longterm construct that engages self and the wider environment. Agency is more than just observable behaviour and self-initiated action; it includes forethought, awareness and intention and requires supportive conditions (Goller, 2017). Within the deliberate professional framework, agency is a capacity for individual action within a complex world of social structure. It is a social and highly interdependent concept that is shaped not only by individual students but also by the social, cultural workplace context and how these position students and enable or hinder agency. Agency builds a strong interrelationship between self, purpose and choice and is an integral component of the concept of the deliberate professional.

\section{Opportunities and challenges in the work-integrated learning context}

Globally, many university bachelor courses make work-integrated learning a mandatory component due to external professional accreditation or employability purposes (Pegg et al., 2012) and not primarily because of a social justice mission to educate morally and socially responsible professionals and citizens (Kreber, 2016). Graduates' ability to follow work procedures and master technical skills are visible and measurable whereas their professional values and ability to purposefully act in a situated practice context are more complex and may require courage. Being eager to fit in and contribute to work processes might help students to experience a smooth socialisation process into a workplace but it also runs the risk of students not learning to think for self, not developing agency and a social conscience (Trede and McEwen, 2015).

Students might not be aware of the assumptions and interests that shape the way work is done which can lead them to accept unreflected, taking-for-granted work practices and developing accidental rather than self-chosen identities. They risk getting out of touch with their own values and what drives their professional behaviour on placement. Students' positioning in the workplace are further complicated because they are not employees and at the bottom of an organisational hierarchy, are there for a short period and have to manage complex professional relationships with their mentors being their assessors at the same time (Cooper et al., 2010). Therefore, postwork-integrated learning interventions are most productive when they provide opportunities for students to have dialogues with peers to explore the tensions, paradoxes and inconsistencies, in short, critical moments that make them stop, pause and rethink what they were doing, thinking or observing (Ripamonti et al., 2018).

\section{The role of post- work-integrated peer reflection}

Work-integrated learning experiences alone are not enough because 'We do not learn from experience. We learn from reflecting on experience' (Dewey, 1933: 78). This quote implies that 
reflecting, a distinctly human activity, enables learning. However, reflection needs to have intention and purpose in order to develop the deliberate professional. In his seminal book 'Knowledge and human interests', Habermas (1972) asserts that specific types of human interest generate and shape specific types of knowledge. This theory is a helpful guide in categorising purposes of reflection with types of knowledge or outcomes to be generated. Habermas identified technical, practical and critical knowledge-constitutive interests. Instrumental interests focus on technical cognitive prediction and generate factual, technical facts and truths which lead to practices that privilege technical performance. Practical interests focus on collaborative cognitive mediation and generates inter-subjectively negotiated meaning which leads to practices that privilege social interactions and consensus. Finally, critical, collaborative interests focus on understanding power relations and generate emancipatory knowledge, important for what is seen as 'natural' practices and social influences. Critical knowledge leads to practices that open up new possibilities and other ways of being (e.g. doing, saying and relating). The purpose, interest and focus on what type of knowledge is to be learned guides what questions and processes are needed for a coherent framework of reflection on experiences.

Discussions need to embrace technical, practical and relational aspects of learning in and from workplace experiences. Ripamonti et al. (2018) suggested that a successful work-integrated learning program "enables students to develop a "free" and critical view of the relationship between themselves, the profession, and the broader context' (11). A study exploring student perspectives on augmenting work-integrated learning experiences found that "utilising postpracticum interventions offers very valuable opportunities to enrich students' educational outcomes, and enhance their employability upon graduation" (Billett et al., p.1292, 2016). The potential and strategies for collective sense-making from work-integrated learning experiences remains overlooked (Billett et al., 2016). The gap in the work-integrated learning literature is the limited research on the practice and value of peer reflection as opposed to self-reflection. Producing individual reflective artefacts about self, others and the host placement is a common assessment practice and integral to work-integrated learning. However, internal self-reflection can stop at superficial levels and is not the same as checking those self-reflections in critical discussions with peers and exploring together how to act otherwise in a similar situation next time (Xie et al., 2008). This collective reflective, action-oriented, future-looking role of peer reflection is limited in the literature of post- work-integrated learning pedagogy despite its potential to help students learn from and with others, and understand the complexity of practice from more than their own perspective (Zegwaard et al., 2017).

The challenge of designing collaborative peer-learning and reflective activities lies in the quality of group interactions (Daniel and Jordan, 2017). The social processes of learning have been described as situated and unfolding activities shaped by diverse individual motivators and assumptions that students bring to collaborative groupwork (Jarvela et al., 2010). From appropriately designed peer learning activities, students can emerge better prepared for the future because they are equipped with multi-dimensional insights and a strengthened sense of who they are becoming as professionals. There is a need to better understand the relationship between students as learners and their engagement with placement supervisors, organisational structures and norms in a host placement and the value of post- work-integrated learning peer reflection to making these relationships and their consequences explicit. The research question that drove this study was, therefore, what is the value of purposefully designed post- work-integrated learning peer-reflections that focus on enablers and inhibitors to educate students to become deliberate professionals? This question is important given work-integrated learning design typically incorporates individually written reflections and lack opportunities for discursive peer reflection which are face-to-face, not assessed and where discussion questions are focused on organisational, relational and cultural issues. Here, learners are encouraged to question their own assumptions through dialogue with others, rather than monologue, and with input from others design plans for new or different future actions.

\section{Method}

Context, recruitment and participants

This study was conducted with students from two universities in Australia. The first institution was located in regional New South Wales and students from their undergraduate degree program in 
Communications with majors in Advertising, Marketing and Public Relations were invited to participate. The second institution is located in Western Australia and students from their underand postgraduate Business programs were invited to participate. These programs included individually written, reflective assessment pieces but none offered a post- work-integrated learning discursive peer reflection opportunity in their curriculum of the type described below.

To recruit participants, the only inclusion criteria were that students in these programs had completed a minimum of 100 hours in a credit-bearing work-integrated learning unit. Ethical approval was obtained from both institutions. To observe confidentiality and anonymity, quotes from participants are referred to as $\mathrm{U}$ for undergraduate, $\mathrm{P}$ for postgraduate, 1 refers to the first institution, 2 to the second institution. Seventy-six participants were recruited via online and faceto-face invitations by lecturers of work-integrated learning subjects. Participants' demographic details are presented in Table 1. Data were gathered between July and October 2017.

\section{Insert Table 1 here}

Post- work-integrated learning peer reflection: the huddle

There was a voluntary and non-assessed or graded, face-to-face, peer-learning workshop that was conducted by the authors, each in one of the two institutions and who were not in a teacherstudent relationship with the research participants. We used the term huddle (see also Fogarty and Schultz, 2010) to refer to the informal, semi-structured nature of our peer learning workshop). Participants were welcomed and briefed that the huddle was a research project and its purpose was to share their perceptions of work-integrated learning experiences in a respectful, ethical environment to critically and collectively make deeper sense of them with the ultimate aim to become more aware of their practice capabilities, practice contexts and to further develop their professional identity and agency.

Participants were purposefully placed into small groups according to their majors to contain placement diversity. They were asked to identify critical moments on placement and discuss why it was important for them, how they felt about it, what actions they took. The group then provided the storyteller with feedback. They were reminded to keep information confidential and discuss their experiences honestly, listen to others in a respectful manner, provide critical yet constructive alternative interpretations and suggest other possibilities on how to act in similar future situations.

The small groups had 30 minutes to discuss the first discussion point and they summarised their discussion on butcher paper and presented it back to the plenary for feedback. Each small group then chose another discussion point from two or more topics: 'describe some differences that you encountered between theory learned in the classroom and actual practice observed/undertaken in the workplace', or 'describe a situation where you encountered conflict between your personal values and ones in the workplace'.

Impact of the huddle experience

After the huddle and plenary feedback sessions, all participants were invited to participate in an individual evaluation which required them to write responses to five open-ended questions to elicit the impact of the huddle and what insights they gained through the peer learning activity. The first two questions asked participants about their placements' learning environment and the last three questions explicitly referred to the huddle activity itself: (i) Name one to three things in your work placement environment that you think helped you move along the scale from novice student to professional; (ii) Name one to three things in your work placement environment that you think stopped you from moving along the scale from novice student to professional; (iii) Name one to three action points that you learned from the activity which you think will help you transition more smoothly to becoming a confident professional; (iv) What are one to three insights you gained about yourself from the workshop activity? and (v) Due to these insights what will you do differently?

Analysis

Data analysis consisted of three phases following Miles and Huberman (1994): description, interpretation and critique. In the first phase, a research assistant collated and accounted for all 
responses. In the interpretation phase, the authors aligned all responses with the four characteristics of the deliberate professional and clustered responses into themes. Finally, these alignments were further discussed among the research team until consensus was reached on the final set of presented themes. The purpose of this approach was to account for similarities and discrepancies (Braun and Clarke, 2006) and better understand the role of this particular postwork-integrated learning peer reflection activity to help students advance their reflection and agency capabilities, as well as to contextualise educating the deliberate professional. The study did not attempt to generalise or make representational statements.

\section{Findings}

The findings are discussed in three sections: enablers of becoming a deliberate professional, inhibitors, and perceived value and impact of the huddle for developing as deliberate professionals.

\section{Enablers for becoming a deliberate professional}

Four themes emerged from responses to question one, 'being guided', 'doing responsible tasks', 'taking initiative' and 'building professional networks'. Each theme is embellished with verbatim responses from participants (Table 2).

Insert Table 2 here

Guidance from others in the workplace was perceived as an important enabler to help students understand what and how they can participate and contribute to the workplace. Participants mentioned the importance of being given responsibility, autonomy and trust. One participant found an 'autonomous environment [to] learn for yourself and from your own mistakes' (U1,7) as important. This quote implies that students want to be given chances to think for self and make mistakes. They showed initiative by seeking opportunities to learn and think for self as stated by these quotes: 'putting into practice some of the things I have learnt at uni' $(\mathrm{U} 1,8)$ and 'using business language and engaging with professionals in all of the office department' $(U 2,44)$. Participants became aware of the importance of networking skills. Networking predominantly included their supervisors and others in the workplace as key enabling factors to become professional. Participants demonstrated limited understanding of the wider social, cultural context of the workplace having an influence on their professional becoming.

Inhibitors of becoming a deliberate professional

Four themes emerged from responses to question two, 'seeing own limited proficiency as an inhibitor', 'poor placement organisation', 'unsupportive workplace environment' and 'conflicting priorities'. Each theme is embellished with verbatim responses from participants (Table 3).

Insert Table 3 here

As the greatest inhibitor, participants mentioned themselves, including their limited experiences and skills which slowed down their progress as professionals. Not having sufficient understanding of what is expected and employers assuming some skill proficiency that they did not have, unsettled their confidence. Some thought they had asked too many questions whereas others thought they did not show sufficient initiative. Participants were uncertain as to what extent they could make changes and they were fearful of making mistakes. The second theme was poor placement structure which included too short length of stay, limited contact in online placement and inadequate tasks. Not being given meaningful job roles with appropriate responsibilities was seen to reduce the potential to develop towards becoming a responsible professional. Participants also listed a mismatch of the placement with own professional interest as an obstacle to advance as professionals. Unsupportive workplace environments, the third theme, focused on projects, supervisors and professionalism. Participants felt limited interactions and guidance by supervisors hindered their development. Observing lapses of professionalism and not being able 
to discuss it was another hindering factor. The fourth theme related to students being conflicted in juggling different priorities at the same time. They continued studying other academic subjects while on placement which led them to feel compromised in fulfilling university and workplace obligations. In summary, participants listed their own limitations, structural and interpersonal issues in the workplace environment as inhibitors especially when they did not receive adequate support, challenge and engagement.

The value of the huddle

Questions three to five elicited what participants learnt through the huddle and their perceptions of its value.

Actions to transition more smoothly to becoming a confident professional

All of the five identified themes related to actions that involved purposefully engaging self with others (Table 4).

Insert Table 4 here

The huddle was designed to help participants become acutely aware of and appreciate the wider practice context. Working with others was the primary theme and demonstrated that participants had the opportunity to learn the social and collaborative process of becoming professional from the huddle. Interestingly, the 'being an active learner' theme featured strongest among postgraduate participants and was exemplified with this quote: 'It is important to voice your concern and don't be afraid of asking questions' (P2, 60). Participants were able to contextualise what it meant to be an active learner by listing future actions they would take, such as cultivating a belief in self by recognising that they have skills that contribute to the workplace and tackling issues rather than avoiding them.

Self-insights gained from the workshop activity

The responses from the participants' post-huddle evaluations were clustered into five themes (Table 5).

Insert Table 5 here

Participants put their workplace experiences into perspective. They realised that they were not the only ones experiencing work-integrated learning as a challenge. This was exemplified by the following comment: 'I'm doing just fine - hospitality is a very challenging industry' (U2,76). Participants acknowledged their own strengths but they also gained self-insights about their limitations and identified future actions to improve, demonstrated by the following observation: 'I learnt that I dealt well under pressure. I learnt that I need to ask for more help' $(U 1,1)$. This participant was self-appreciative of how they handled a challenging situation but they also learnt that there is room for improvement. Through reflecting on their experiences participants discussed the collaborative nature of learning in placements.

Transforming insights into future actions

Responses to this final question were clustered into three themes: getting more involved, being more confident and being better prepared next time (Table 6).

Insert Table 6 here

Participants demonstrated that they gained insights from the huddle - and their work experience - activity about agency, for example, asking for help and listening were seen as active learning skills. Participants understood that they needed to take responsibility for their professional journey. They wanted to reflect collectively more often in order to clarify what is happening around them so they could feel more in control of what to do next. 'Be more confident and less anxious 
as I know everyone goes through a similar ordeal when entering the workplace' $(U 2,55)$. The strongest theme related to being better prepared, taking responsibility for own learning, taking more reflective pauses as well as action-oriented initiative. 'Learn to work under pressure', 'speak my mind' and 'improve communications with others' are good examples of how participants claim that they will transform insights gained from the huddle into future actions.

\section{Discussion and implications}

The mixed responses of the evaluation demonstrate that participants gained a diverse range of insights on their journey towards becoming deliberate professionals. The themes presented above highlight insights and future action plans that participants gained which they were able to explicitly articulate in their responses. Overall, however, there was limited evidence of emancipatory progression. We conjecture that this may be the result of participants' lack of preparation and sensitisation before placements/internships to engage with ethical dilemmas in the workplace. The findings are first interpreted with respect to the four characteristics of the deliberate professional. Next, we consider future use of purposeful huddles in work-integrated learning and, finally, the usefulness of huddles in the wider curriculum.

\section{Students as deliberate professionals}

The first characteristic of the deliberate professional, pondering on the complexity of practice and workplace cultures and environments, remained underexplored. Participants' discussions did not venture far beyond their interpersonal professional relationship with their supervisor. They had limited appreciation of organisational, ethical, political and cultural dimensions that play into the way they learn to become professionals.

The second characteristic of the deliberate professional, understanding what is probable, possible and impossible in relation to existing and changing practices, was partially developed. Findings demonstrate that participants reduced their understanding of what is probable, possible and impossible to their own sphere of influence and that of their workplace supervisor. They had an overly interpersonal perspective and only few mentioned structural changes and possibilities that the university or workplace could take up to ensure everybody can make the most from workintegrated learning. The huddle enabled participants to collectively identify constructive ideas that they themselves can possibly change. The notion of what would be impossible was not discussed. This could suggest that participants' collective reflections did not venture into considering impossibilities and utopian thinking or they thought it unproductive to think of impossibilities. Not musing with other (im)possibilities was a missed opportunity to cultivate creative thinking and confirms Littleton et al.'s (2012) call for more creative thinking.

The third characteristic of the deliberate professional, taking a deliberate stance in positioning oneself in practice as well as in making technical decisions, was well developed with the huddle activity. Participants demonstrated the ability to more thoughtfully and purposefully position themselves within the practice situations they had experienced. They identified their capabilities and limitations explicitly and also became aware that they needed to play an active role in negotiating what professional tasks were allocated to them. They demonstrated that they were determined to intentionally position themselves in their future practice which fostered their identity agency and the interdependent responsibility of student and supervisor.

The fourth characteristic of the deliberate professional, being aware of and responsible for the consequences of actions taken, was further developed through the huddle. Participants became aware that they had to take responsibility for their own learning and actions despite being inexperienced and novices. This resonates with Clouder's (2009) findings that students need to seize opportunities for more agency and responsibility in the workplace. Participants avoided asking questions because they did not want to be perceived as a burden. They were reluctant to critique unethical or inefficient practices that they had observed in the workplace. Through peer reflection and exploring together what else could have been done, participants understood that rather than ignoring they had to act on incidents in the workplace.

Future use of huddles in work-integrated learning 
The huddle is a safe, peer learning activity that provided an opportunity for participants to learn from each other's perspectives and firm up intentional, thoughtful and action-oriented commitments for future practices in self and peers. Participants realised that some tensions in the workplace are almost inevitable and must be engaged with. Without getting involved and asking questions, participants felt that they could easily lose self-confidence and disengage. Future huddles should be introduced ahead of work-integrated learning experiences to sensitise students to observe and critically engage with the complexity of practice beyond an individual focus. This huddle had limited impact on participants' understanding of the wider social context and structural challenges. Future huddles could be used to more specifically draw out the impact of work cultures and power relations on developing professional agency about possibilities and choices (Littleton et al., 2012) and becoming a deliberate professional. The scope to engage in critical discussion could be improved with targeted topics on socio-cultural contexts and preparation for critical questioning skills (Trede and McEwen, 2015). Huddles could be conducted with underrepresented student groups to purposefully boost their sense of agency to overcome structural non-inclusive work-integrated learning practices in the workplace (O'Shea, 2016).

\section{Using huddles in the curriculum}

The findings have implications for using the huddle activity in the curriculum to strengthen peer learning from work-integrated learning experiences and embed educating the deliberate professional. An expert facilitator and peer assessment could be included to increase the effectiveness and quality of peer reflection (Mulder et al., 2014). The huddle in small groups can also be used as an informal, non-assessed peer learning activity. It can be embedded as a 'breakout' component of larger classes teaching remembering that huddles can be used only in small groups. Huddles can create conditions for peer learning that opens up thinking about other possibilities and hence fosters critical and creative thinking skills.

From this study, we conclude that our research findings support the huddle as an active, peer learning strategy which may help students progress in their journey towards becoming a deliberate professional. As evidenced by participants' insights into future actions, they understood that dwelling on the novice status and waiting for more guidance would not progress them to become deliberate professionals. Participants claimed to have developed their learner agency because they learnt that they had to take responsibility for being better prepared, seek more engagement in the workplace, and seize opportunities for networking. However, participants' professional and social agency was limited because discussions of structural and cultural constraints were not further explored. Post- work-integrated learning peer reflections contribute to educating deliberate professionals but we recommend a stronger focus on consciousness raising of socio-cultural conditions and enhanced questioning skills to help students explore how to engage with them.

As with all studies, there are limitations. The sample size is not large. It spans only two disciplines, mostly undergraduates and from only two institutions in one country. There were significantly more female than male participants. The survey responses did not provide for rich texts. A longitudinal study design would help to address questions that the study described here does not answer. These could include how the huddle activity was an impetus for more action-oriented reflections in future challenging practice situations. Future research could compare the value of the huddle with the value of meaningful work experiences. Future work is also needed to advance insights into the complexity and challenges of discussing ethical dilemmas in group work settings and what role purposeful preparation before placement experiences can play to sensitise students. Future work is also needed in terms of exploring reflective small group work more closely by for example, gender, age, underrepresented student groups, language diversity. It is also important to acknowledge that not all students may benefit from group work and it may not always be feasible in certain learning contexts, such as online or where there are large numbers of students. A huddle, as a form of small group work, may therefore be a positive experience for many but this study does not claim to produce evidence that it is 'better' than individual learning (as this was not part of the study design and not examined as such).

Actual behaviour was not measured; this study relied on self-reporting. Future work is needed to see whether or not any activity, whether a huddle or not, results in actual changes in the sayings, doings and relatings in the workplace. Data was gathered only from students and not from their supervisors or those who employed the students in the workplace. Finally, it is normally the case 
that a minority of students undertake such a work placement. Most students graduate without having undertaken a formal period of work placement as part of their studies. It remains to be seen whether those who do not undertake such a work-based learning experience are at a disadvantage/are different in terms of being a deliberate professional in the workplace after they graduate. That is, are they less likely to take responsibility for being better prepared, less likely to seek more engagement in the workplace, and less likely to seize opportunities for networking than those who have undertaken a period of work placement.

There are implications for future research. The progression to become deliberate professionals is a relational, collaborative, agentic learning trajectory that cannot be travelled alone. Future research should explore work-integrated learning supervisors and academics' reflections of their contribution to socio-cultural and relational aspects that shape what and how students learn from placement experiences. Huddles could be researched in work-integrated learning placements where participants could include students, supervisors, their other colleagues who work with students. A workplace huddle could explore how workplace cultures create or hinder inclusive access and supportive conditions for student learning. With increasing uptake of online learning, the use of online huddles for educating the deliberate professional should be researched. These could provide just-in-time collective reflection across workplace settings to help all stakeholders involved to make the most of work-integrated learning experiences.

\section{References}

Arendt H (1998) The Human Condition. Chicago: The University of Chicago Press.

Barnett R (2012) Framing education for practice. In Higgs J, Fish D, Goulter I, Loftus S, Reid JA and Trede $\mathrm{F}$ (eds.) Education for Future Practice. Rotterdam: Sense Publishers, pp. 15-28.

Billett S (2011) Curriculum and Pedagogical Bases for Effectively Integrating Practice-based Experiences - Final Report. Strawberry Hills, NSW: Australian Learning and Teaching Council. Billett $S$ (2015) The practices of using and integrating practice-based learning in higher ducation. In Kennedy M, Billett S, Gherardi S and Grealich L (eds.) Practice-based Learning in Higher Education. Professional and Practice-based Learning. Dordrecht: Springer, pp. 1530.

Billett S, Cain M and Hai Le A (2018) Augmenting higher education students' work experiences: preferred purposes and processes, Studies in Higher Education 43(7): 1279-1294.

Bourdieu P (1994) Raisons Pratiques: Sur la Théorie de L'action. Paris: Editions du Seuil.

Braun V and Clarke V (2006) Using thematic analysis in psychology. Qualitative Research in Psychology 3(2): 77-101.

Brookfield SD (2012) Teaching for Critical Thinking: Tools and Techniques to Help Students Question their Assumptions. San Francisco: Jossey-Bass.

Clark G, Marsden J, Duncan Wyatt J, Thompson L, Walker M (2015) 'It's everything else you do...': alumni views on extracurricular activities and employability. Active Learning in Higher Education 16(2): 133-147.

Clouder L (2009) 'Being responsible': students' perspectives on trust, risk and work-based learning. Teaching in Higher Education 14(3): 289-301.

Connell R (2019) The Good University: What Universities Actually Do and Why It's Time for Radical Change. Clayton, Victoria: Monash University Publishing.

Cooper L, Orrell J and Bowden M (2010) Work Integrated Learning: A Guide to Effective Practice. New York: Taylor and Francis.

Daniel SR and Jordan ME (2017) Effects of a heedful interrelating intervention on collaborative teams. Active Learning in Higher Education 18(3): 199-212.

Dewey J (1933) How We Think: A Restatement of the Relation of Reflective Thinking to the Educational Process. Lexington, MA: Heath.

Eteläpelto A (2008) Perspectives, prospects and progress in work-integrated learning. In Billett $\mathrm{S}$, Harteis $\mathrm{C}$ and Eteläpelto A (eds.). Emerging Perspectives of Workplace Learning. Rotterdam: Sense, pp. 233-248.

Eteläpelto A, Vähäsantanen K, Hökkä P and Paloniemi S (2013) What is agency? Conceptualising professional agency at work. Educational Research Review 10(1): 45-65.

Freire P (1973) Education for Critical Consciousness. New York: Seabury Press.

Fogarty C and Schultz S (2010) Team huddles: the role of the primary care educator. The Clinical Teacher 7(3): 157-160. 
Goller M (2017) Human Agency at Work: An Active Approach towards Expertise Development. Wiesbaden: Springer.

Habermas J (1972) Towards a Rational Society (J.J. Shapiro, Trans.). London: Heinemann.

Jarvela S, Volet, S and Jarvenoja H (2010) Research on motivation in collaborative learning: Moving beyond the cognitive-situative divide and combining individual and social processes. Educational Psychologist 45(1): 15-27.

Kemmis S (2012) Phronesis, experience and the primacy of praxis. In Kinsella A and Pitman A (eds.). Phronesis as Professional Knowledge: Practical Wisdom in the Professions. Rotterdam: Sense, pp. 147-162.

Knight $\mathrm{P}$ and Yorke M (2006) Employability: Judging and Communicating Achievements. York: Higher Education Academy

Kreber C. (2016). Educating for Civic-mindedness: Nurturing Authentic Professional Identities through Transformative Higher Education. New York, NY: Routledge.

Littleton K, Taylor S and Eteläpelto A (2012) Special issue and introduction: Creativity and creative work in contemporary working contexts. Vocations and Learning 5(1): 1-4.

Miles M and Huberman A (1994) Qualitative Data Analysis. Thousand Oaks, CA: Sage.

Mulder RA, Pearce JM and Baik C (2014) Peer review in higher education: Student perceptions before and after participation. Active Learning in Higher Education 15(2): 157-171.

Newman M (2006) Teaching Defiance: Stories and strategies for activist educators. San Francisco, SA: Jossey-Bass.

OECD (2013) Assessment of Higher Education Learning Outcomes. Feasibility study Report. Vol 2. Data Analysis and National Experiences.

O'Shea S (2016) Avoiding the manufacture of 'sameness': first-in-family students, cultural capital and the higher education environment. Higher Education 72(1): 59-78.

Pegg A, Waldock J, Hendy-Isaac S and Lawton R (2012) Pedagogy for Employability. York, Higher Education Academy.

Ripamonti S, Galuppo L, Andreina B, Ivaldi S and Scaratti G (2018) Reconstructing the internship program as a critical reflexive practice: the role of tutorship. Teaching in Higher Education 23(1): $1-18$.

Sachs J, Rowe A with Wilson M (2016) 2016 Good Practice Report - Work Integrated Learning. Office of Learning and Teaching, Canberra.

Trede F and McEwen C (2016) Scoping the deliberate professional. In Trede F and McEwen C (eds.) Educating the Deliberate Professional: Preparing for Future Practices. Dordrecht: Springer, pp. 15-28.

Trede F and McEwen C. (2015) Critical thinking for future practice, In M. Davies and R. Barnett (Eds.), Palgrave Handbook of Critical Thinking in Higher Education (pp. 457-475). New York, Palgrave Publishers.

Xie $\mathrm{Y}$, Fengfeng $\mathrm{K}$ and Sharma $\mathrm{P}$ (2008) The effect of peer feedback for blogging on college students' reflective learning processes. Internet and Higher Education 11(1):18-25.

Zegwaard KE, Campbell MT and Pretti J (2017).Professional identities and ethics: The role of work-integrated learning in developing agentic professionals. In Drysdale $\mathrm{M}$ and Bowen $\mathrm{T}$ (eds.) Work-integrated Learning in the 21st Century. Bingley, UK: Emerald Publishing Limited, pp. 145160.

Zepke $N$ and Leach L (2010) Improving student engagement: ten proposals for action. Active Learning in Higher Education 11(3): 167-177. 
Table 1. Participant Demographics

\begin{tabular}{|c|c|c|c|c|c|c|c|c|c|}
\hline \multirow{3}{*}{ Characteristic } & \multirow{3}{*}{ Sub-group } & \multicolumn{2}{|c|}{ Institution 1} & \multicolumn{4}{|c|}{ Institution 2} & \multicolumn{2}{|c|}{ Total } \\
\hline & & \multirow[b]{2}{*}{$\mathbf{N}$} & \multirow[b]{2}{*}{$\%$} & \multicolumn{2}{|c|}{ UG } & \multicolumn{2}{|c|}{ PG } & \multirow[b]{2}{*}{$\mathbf{N}$} & \multirow[b]{2}{*}{$\%$} \\
\hline & & & & $N$ & $\%$ & $N$ & $\%$ & & \\
\hline \multirow{2}{*}{ Gender } & Male & 3 & 13.0 & 14 & 42.4 & 7 & 35.0 & 24 & 31.6 \\
\hline & Female & 20 & 87.0 & 19 & 57.6 & 13 & 65.0 & 52 & 68.4 \\
\hline \multirow{4}{*}{ Age } & $0-24$ years & 20 & 87.0 & 20 & 60.6 & 2 & 10.0 & 42 & 55.3 \\
\hline & $25-29$ years & 1 & 4.3 & 5 & 15.2 & 11 & 55.0 & 17 & 22.4 \\
\hline & $30-39$ years & 1 & 4.3 & 6 & 18.2 & 7 & 35.0 & 14 & 18.4 \\
\hline & $40+$ years & 1 & 4.3 & 2 & 6.1 & & & 3 & 3.9 \\
\hline \multirow{2}{*}{ Residency } & Domestic & 23 & 100 & 22 & 66.7 & 3 & 15.0 & 48 & 63.2 \\
\hline & International & 0 & 0 & 11 & 33.3 & 17 & 85.0 & 28 & 36.8 \\
\hline \multirow{2}{*}{$\begin{array}{l}\text { Current working } \\
\text { status }\end{array}$} & Working & & & 19 & 57.6 & 10 & 50.0 & 29 & 54.7 \\
\hline & Not working & & & 14 & 42.4 & 10 & 50.0 & 24 & 45.3 \\
\hline
\end{tabular}


Table 2. Themes and subthemes of enablers for becoming a deliberate professional

\begin{tabular}{|c|c|}
\hline Themes & Quotes \\
\hline \multirow{5}{*}{ Being guided } & Understanding task requirement; receiving clear job direction \\
\hline & Receiving help, assistance, guidance, advice, support from staff/team \\
\hline & Receiving feedback from staff/guests/clients; mentoring \\
\hline & Learning in a nurturing and supportive environment \\
\hline & Being in a good workplace culture \\
\hline \multirow{4}{*}{$\begin{array}{l}\text { Doing responsible } \\
\text { tasks }\end{array}$} & Actual projects, variety of tasks; tasks related to discipline \\
\hline & Given autonomy (i.e. to make decision; being trusted) \\
\hline & Learning new skills (i.e. technical, software, etc); improving skills \\
\hline & Participating in group/team work; meetings \\
\hline \multirow[t]{7}{*}{ Taking initiative } & Asking questions; providing personal opinions \\
\hline & Observing and learning from others (e.g. ethics, work) \\
\hline & Learning from own mistakes; listening \\
\hline & Showing initiative, proactiveness \\
\hline & Being confident, positive, persistent, resilient, adaptable \\
\hline & Dealing with pressure \\
\hline & Willingness to learn, dedicated; push oneself \\
\hline \multirow{3}{*}{$\begin{array}{l}\text { Building } \\
\text { professional } \\
\text { networks }\end{array}$} & Relationship building with industry professionals \\
\hline & Talking to others about their experience; interns, etc \\
\hline & Networking with professional in chosen profession \\
\hline
\end{tabular}


Table 3. Inhibitors of becoming a deliberate professional

\begin{tabular}{|c|c|}
\hline Theme & Sub-theme \\
\hline \multirow[t]{9}{*}{ Own limited proficiency } & Limited understanding of terminology/policies, etc \\
\hline & Limited practice / practical experience \\
\hline & Theory and knowledge (e.g. restricted/limited; misaligned) \\
\hline & Poor time-management skills \\
\hline & Asking too many questions; creating conflict; making changes \\
\hline & Lacking confidence; nervous; uncertain \\
\hline & Intimidated by staff; fear of making a mistake \\
\hline & Lack of initiative/proactiveness/incorporate own ideas \\
\hline & Assumed proficiency (by employer, e.g. Software skills, Specialised programs \\
\hline \multirow{8}{*}{ Poor placement structure } & Position held (role seen by staff/moved often) \\
\hline & Size of the organisation (too small) \\
\hline & Poor choice of placement; outside area-of-interest \\
\hline & Limited time in placement; lack of continuity \\
\hline & Lack of variety, repetitive tasks, quality/quantity \\
\hline & Limited responsibility \\
\hline & Limited learning in specific skills/difficult tasks \\
\hline & Online placement (e.g. limited contact with staff/idea of professionalism) \\
\hline \multirow{5}{*}{$\begin{array}{l}\text { Unsupportive workplace environment } \\
\text { (employer) }\end{array}$} & Unavailability of staff; professional assistance; workplace interaction \\
\hline & Limited projects/tasks or relevant tasks \\
\hline & Goals not achieved or not followed; cooperation of staff \\
\hline & Lack of professionalism, organisation \\
\hline & Lack of direction, guidance, mentorship \\
\hline Conflicting priorities/constraints & $\begin{array}{l}\text { University obligations } \\
\text { Time/other commitments }\end{array}$ \\
\hline
\end{tabular}


Table 4. The value of the huddle

\begin{tabular}{|c|c|}
\hline Theme & Sub-themes \\
\hline \multirow{6}{*}{$\begin{array}{l}\text { Working with } \\
\text { others }\end{array}$} & Communication skills (written, verbal, discussion) \\
\hline & Asking for help (employees, others); ask questions; speaking up \\
\hline & Managing conflict; resolving a dilemma \\
\hline & Understanding cultural difference \\
\hline & Teamwork, collaboration \\
\hline & Interpersonal skills; being friendly; professional \\
\hline \multirow{6}{*}{$\begin{array}{l}\text { Being an active } \\
\text { learner }\end{array}$} & Eager to learn; learn as you go; researching; doing tasks; taking notes \\
\hline & Learn from others, from conflict, from mistakes \\
\hline & Be proactive; find solutions; initiative \\
\hline & $\begin{array}{l}\text { Acceptable be a novice; learning takes time; being accountable; doing } \\
\text { prac }\end{array}$ \\
\hline & Confidence in working independently or in a team; confidence in ability \\
\hline & $\begin{array}{l}\text { Challenge oneself; get out of comfort-zone; continuous self- } \\
\text { improvement }\end{array}$ \\
\hline \multirow[t]{4}{*}{ Being aware } & Others are in the same situation; same struggles/transitioning \\
\hline & Discussions with others: people's experience, advice, tips, problems \\
\hline & Self-awareness; self-improvement \\
\hline & Reflection \\
\hline \multirow{5}{*}{$\begin{array}{l}\text { Knowing and } \\
\text { applying own } \\
\text { ability }\end{array}$} & Practical knowledge \\
\hline & Strategic thinking; critical thinking; tackling issues \\
\hline & Creative ideas; innovative \\
\hline & Applying academic knowledge \\
\hline & Developing specific skills/knowledge \\
\hline \multirow{6}{*}{$\begin{array}{l}\text { Workplace: } \\
\text { Appreciating } \\
\text { Workplace } \\
\text { cultures to better } \\
\text { position self }\end{array}$} & Being in a comfortable environment; professional environment \\
\hline & Professional/comfortable relationship with staff, peers, supervisor, etc \\
\hline & Workplace expectations \\
\hline & Tenure: length/time spent at one location \\
\hline & Time management skills \\
\hline & Emotional intelligence \\
\hline
\end{tabular}


Table 5. Self-insights gained from the huddle

\begin{tabular}{|c|c|}
\hline Theme & Sub-themes \\
\hline \multirow{8}{*}{$\begin{array}{l}\text { Relational } \\
\text { awareness }\end{array}$} & Shared similar experiences or problems (everyone is in the same boat) \\
\hline & Enjoyed interning; grateful for the experience; positive experience \\
\hline & Would like to share challenges with others \\
\hline & Better experience than others; some people aren't industry ready \\
\hline & $\begin{array}{l}\text { Network; make friends with industry; be social; positive relationships; } \\
\text { like a social environment }\end{array}$ \\
\hline & Workplace is complex; not all industries are the same \\
\hline & Opinion on university academic focus \\
\hline & Relationship with theory Vs work (students do not draw connections) \\
\hline \multirow[t]{3}{*}{$\begin{array}{l}\text { Insights into own } \\
\text { agency }\end{array}$} & $\begin{array}{l}\text { Identified ways to improve; how much l've learned; improvement is } \\
\text { important; be proactive; reflect on skills/abilities }\end{array}$ \\
\hline & $\begin{array}{l}\text { Responsible for own actions; acknowledge incidents at the workplace; } \\
\text { too hard on myself }\end{array}$ \\
\hline & Ask for more help; ask questions; speak-up; need clear instructions \\
\hline \multirow[t]{4}{*}{$\begin{array}{l}\text { Awareness of own } \\
\text { strengths }\end{array}$} & $\begin{array}{l}\text { Problem solving; understanding barriers; contributing ideas; showing } \\
\text { initiative; dealing with pressure; adapting to new environment }\end{array}$ \\
\hline & Communication \& team working skills \\
\hline & Able to take constructive feedback \\
\hline & Time management skills \\
\hline \multirow{6}{*}{$\begin{array}{l}\text { Awareness of own } \\
\text { limitations }\end{array}$} & Lack of confidence; develop positive thinking \\
\hline & Not good under pressure; stay calm when addressing a problem \\
\hline & Limited knowledge or skills; did not apply theories \\
\hline & Difficulties in communicating, reflecting \\
\hline & $\begin{array}{l}\text { Be proactive; show initiative; take feedback; understand other's } \\
\text { perspectives }\end{array}$ \\
\hline & Need to develop goals; know career path \\
\hline \multirow{3}{*}{$\begin{array}{l}\text { Important aspects } \\
\text { of internship / } \\
\text { workplace }\end{array}$} & $\begin{array}{l}\text { Communication; discussions; listening skills; researching; } \\
\text { professionalism }\end{array}$ \\
\hline & Work / life balance is important; good time management skill \\
\hline & How to handle conflict; challenges \\
\hline
\end{tabular}


Table 6. Transforming insights into future actions

\begin{tabular}{|l|l|}
\hline Theme & Sub-themes \\
\hline Get more involved & Ask for help; ask more questions; consult others; listen \\
\cline { 2 - 2 } & Speak my mind; share ideas; engage more; be more involved; proactive \\
\cline { 2 - 2 } & Continue to help/teach others at uni \\
\cline { 2 - 2 } $\begin{array}{l}\text { Be more confident } \\
\text { and resourceful }\end{array}$ & $\begin{array}{l}\text { Othect and discuss experiences; gain positive and negative insights } \\
\text { independent }\end{array}$ \\
\cline { 2 - 2 } & $\begin{array}{l}\text { Learn to work under pressure; Maintain a positive attitude; be } \\
\text { professional; gain a job where I will be happiest }\end{array}$ \\
\cline { 2 - 2 } & Time management; communicate effectively; networking \\
\cline { 2 - 2 } & $\begin{array}{l}\text { Try harder; get stuck in; improve communications with others; } \\
\text { professionalism; }\end{array}$ \\
\hline Be prepared & $\begin{array}{l}\text { Read more industry related information; be more open minded; focused; } \\
\text { Give more importance to practical knowledge }\end{array}$ \\
\cline { 2 - 2 } & Do not complete another internship \\
\cline { 2 - 2 } & Do more internships; grateful for experience \\
\hline
\end{tabular}

\section{Acknowledgment}

Funding information: Office for Learning and Teaching (ID15-4902)

Word count: 7,533 